\title{
Design and Implementation of a Test Device for Determining the Capacity of Industrial Battery Banks
}

\author{
Z. ZÜREY, K. SABANCI, and S. BALCI
}

\begin{abstract}
In this study, a test device is developed to measure the capacities and performances of high capacity battery banks and to detect broken cells. Batteries lose their performance over time due to their chemical properties, storage and usage conditions, production technologies. Some batteries may even become completely unusable long before the promised life cycle. Through this test device, the instant capacity of the battery banks is measured. Based on the data obtained, quantitative data such as state of health and nominal energy of the battery bank are calculating. It is determined whether the battery bank will meet the need according to its intended use. In this way, it is ensured to prevent possible losses by determining the battery cells or groups that need to be changed.
\end{abstract}

Index Terms - Battery capacity test device, industrial battery banks, buck converter, power electronics.

\section{INTRODUCTION}

$\mathrm{W}$ ITH THE developing technology, usage of the batteries is becoming widespread day by day. As storage elements, batteries are frequently used in electric vehicles (EVs), uninterrupted power supply (UPS) and renewable energy sources [1]. In addition, while the efforts to reduce the production costs of the batteries have been going on in recent years, their performance has been increasing gradually.

The world's energy needs were mostly met with fossil fuels. During this period, very important researches has been done on renewable energy sources, which do not have a negative impact

ZEKİ ZÜREY, is with Department of Electrical and Electronics Engineering University of Karamanoğlu Mehmetbey University, Karaman, Turkey, (e-mail: zurey.z@gmail.com).

(D) https://orcid.org/0000-0003-4219-1274

KADİR SABANCI, is with Department of Electrical and Electronics Engineering University of Karamanoğlu Mehmetbey University, Karaman, Turkey, (e-mail: kadirsabanci@kmu.edu.tr).

https://orcid.org/0000-0003-0238-9606

SELAMI BALCI, is with Department of Electrical and Electronics Engineering University of Karamanoğlu Mehmetbey University, Karaman, Turkey, (e-mail: sbalci@kmu.edu.tr).

(iD) https://orcid.org/0000-0002-3922-4824

Manuscript received February 15, 2020; accepted September 13, 2020. DOI: $10.17694 /$ bajece. 689724 on natural life [2]. Energy generation systems using renewable energy sources are generally used in mountainous areas where electricity transmission is difficult and expensive, on islands with their own electricity network, to meet the electrical energy needs of settlements [3]. As a result, battery banks are preferred for the purpose of temporarily storing electricity.

The most preferred application areas for energy storage systems installed with batteries are used in UPS systems for emergency and communication systems. The widespread use of energy sources such as photovoltaic and wind, the need for energy storage systems is increasing [2].

Another application area of the battery banks is UPS systems. It is inevitable to use UPS in critical systems. In critical applications, high capacity battery banks are used as backup energy sources to protect the system against power failure [4]. While using generator systems fed fossil fuel previously, the use of UPS systems with large battery banks has become widespread in parallel with the development of battery technology.

However, battery cells lose their health due to use. It may cause life-threatening and financial losses in case of failure or malfunction of the system it supplies energy. Disruption of the cell connected in series can cause imbalances in the parallel connection. Periodic tests are carried out to prevent such malfunctions. In these tests, cell voltages are checked one by one to detect broken cells [5].

One of the most common uses of battery banks is electric vehicles. The use of electric vehicles is increasing with great momentum. Although the search for alternatives continues, battery banks are used in today's electric vehicles for energy storage. It is not suitable for the range of vehicles to continue to be used in the electric vehicles of the battery banks on the electric vehicles, whose capacity has decreased below $70 \%$.

However, these battery banks are still very valuable and can be used in many areas. As a matter of fact, energy storage facilities can be established on the basis of grids with used battery banks removed from electric vehicles.

Testing and monitoring the health of the battery banks is very important in terms of cost and work safety. With the test device developed, important data about the health of battery banks were obtained.

Schollet.al. (1971) got the first automatic battery tester 
patent. This device has fixed load groups. Any of these load groups can be selected manually. In addition, instantaneous voltage and instantaneous current can be recorded by a mechanical recorder [6]. Berglund et. al. (1997) with the device they developed, aimed to test the low voltage batteries by discharging and charging them at $2400 \mathrm{~W}$ rated power. There are two options for discharge. While the first option can be discharged for a long time with a low load, the second option can be discharged for a short time with a high load [7]. Bertnesset.al. (2000) tried a different method in the battery test. The device developed in this study determines a battery characteristic according to the values obtained in its tests and generates code according to this characteristic. According to this code produced, comments about battery health are made [8]. Brink et.al. (2000) studied a different battery characterization method. With the device they developed, they measured the terminal impedance of the battery under a few fixed loads. They tried to estimate the battery capacity by interpreting the data they obtained [9]. Anbuky et.al. (2005) developed a battery characterization method based on computation. In this method, the amount of voltage drop is taken into account when the battery is connected to a fixed load. This value is interpreted as a result of mathematical operations and information about battery capacity is obtained [10]. Coleman et.al. (2008) developed the dual pulse method to determine the AHC, SoC and SoH values of a battery. The first pulse balances the battery over its previous history. The second pulse determines the battery parameters. The new approach has been experimentally validated [11].

In previous studies, one of the fixed load options was preferred and the batteries were discharged. In some studies, short term tests were conducted. The results obtained were evaluated and estimations about battery capacity were made.

The datasheets of commercial companies are used when choosing a storage element with the desired technical specifications for storage unit installation for a system or device. After the storage unit is installed, the batteries are expected to meet certain criteria throughout the life of the system. However, due to their chemical structure, the batteries lose their health depending on the usage and duration of use. In this context, the health and performance of the batteries used in the industrial field should be at a minimum level for reasons such as both commercial and safety requirements. If the battery used is unable to meet the system requirements, it may lead to some malfunctions, system failure or even dangerous situations over time.

In this study, a fully automatic test device has been developed to measure the capacities and performances of the high capacity battery banks and to detect broken cells. With this test device, long term full tests were performed instead of the estimation and calculation methods and real results were obtained. In this way, problems arising from the chemical structures of the batteries and ignored in the calculations can be identified. In addition, thanks to the automated device, the test conditions were clearly determined. It can be shown as an example of the usage areas of the developed tester, electric cars, electric buses, electric motorcycles and bicycles, all electric construction machines such as forklifts, mini loaders and excavators, battery banks used for UPS purposes, battery banks of small-scale solar power plants, battery banks used in micro grid applications.

\section{THEORETICAL EXPLANATION OF THE BUCK CONVERTER CIRCUIT}

The Buck converter is a non-isolated DC to DC converter that reduces the output voltage below the input voltage. Non isolated DC to DC converters have a disadvantage that, although simple and widely used, the voltage conversion rates are limited. So, when high conversion rate is required, isolated DC to DC converters are used. The buck converters are simple. It requires only one switching component. Therefore, their efficiency is high and their costs are low. High efficiency can be achieved by the use of switching elements which consume less power and are controlled at higher frequencies. Parallel to the developments in electronics, BJT, MOSFET and IGBT are used as switching elements in dc-dc converters in recent years. However, IGBT and MOSFETs are preferred in high-power converter applications $[12,13]$. Fig. 1 shows the basic diagram of the buck converter.

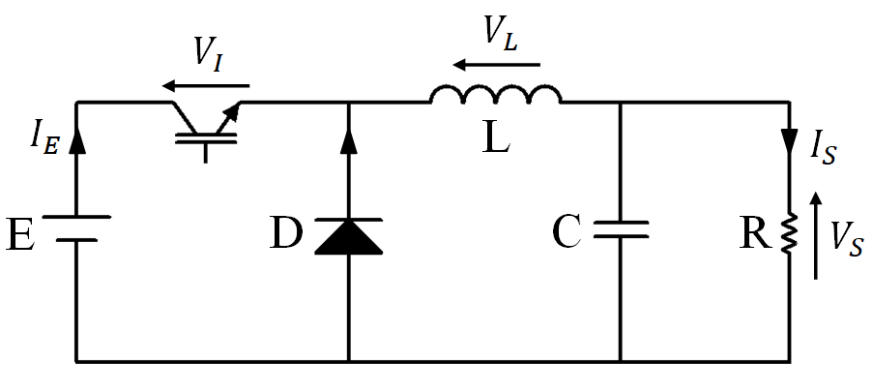

Figure. 1. Buck converter circuit

The input impedance of a DC to DC converter is the impedance seen at the input source. The output impedance is the output voltage response of the converter for the excitation of the current when the duty rate and the input voltage are constant [14]. R resistance represents load. L and C form a filter to limit oscillations on voltage and output current. Ideally, IS and $V_{S}$ are continuous [15]. When $L$ is closed, the voltage drop on the inductor is:

$$
\mathrm{V}_{\mathrm{L}}=\mathrm{E}-\mathrm{V}_{\mathrm{S}}
$$

The current through the inductor increases linearly. As the diode is reverse-biased, no current flows over it. Typical waveforms of current and voltage in a converter are shown in Fig. 2 [15].

When the switch $\mathrm{T}$ is opened, the diode is forward biased. The voltage across the inductor is $V_{L}=-V_{S}$. The current $I_{L}$ decrease. The energy stored in inductor form:

$$
\mathrm{E}_{\mathrm{L}}=\frac{1}{2} \mathrm{LI}_{L}^{2}
$$

The rate of change of $\mathrm{I}_{\mathrm{L}}$ can be calculated from:

$$
\mathrm{V}_{\mathrm{L}}=\mathrm{L} \frac{d \mathrm{I}_{\mathrm{L}}}{d t}
$$


with $V_{L}$ equal to $E-V_{S}$ during the on-state and to $-V_{S}$ during the off-state. Therefore, the increase in current during the onstate is given by:

$$
\Delta \mathrm{I}_{\mathrm{L}_{\mathrm{on}}}=\int_{0}^{T_{o n}} \frac{\mathrm{V}_{\mathrm{L}}}{\mathrm{L}} \mathrm{dt}=\frac{\mathrm{E}-\mathrm{V}_{\mathrm{S}}}{\mathrm{L}} \mathrm{t}_{\mathrm{on}=\alpha \mathrm{T}}
$$

where $\alpha$ is called the duty cycle with a value between 0 and 1. The decrease in current during the off-state is given by:

$$
\begin{gathered}
\Delta \mathrm{I}_{\mathrm{L}_{\text {off }}}=\int_{t_{\text {on }}}^{\mathrm{T}} \frac{\mathrm{V}_{\mathrm{L}}}{\mathrm{L}} \mathrm{dt}=-\frac{\mathrm{V}_{\mathrm{S}}}{\mathrm{L}} \mathrm{t}_{\text {off }=(1-\alpha) \mathrm{T}} \\
\Delta \mathrm{I}_{\mathrm{L}_{\text {on }}}+\Delta \mathrm{I}_{\mathrm{L}_{\text {off }}}=0 \\
\frac{V_{S}}{E}=\alpha
\end{gathered}
$$

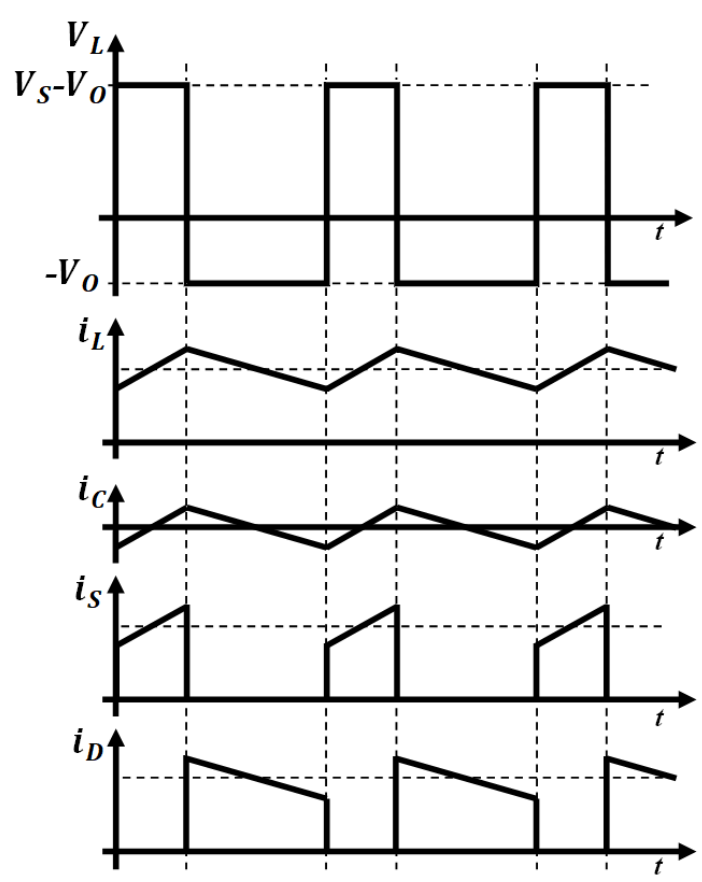

Figure. 2. The basic waveforms of the buck converter circuit

\section{The Basic Circuit Structure Of The Designed SYSTEM}

In the buck converter circuit, the main purpose is to provide a constant level of voltage to the load by trimming the voltage with a controlled switching element. An LC filter and a diode parallel to this filter are used to damp oscillations caused by voltage clipping.

In the designed test device, it is aimed to load the battery bank with a constant current using a resistance group and a controlled switching element.

Although wire wound resistances are of small size, lightweight and very high power, they are not suitable for use in an environment where a battery bank is available since they reach very high temperatures. For this, 4 resistances of $1.5 \mathrm{~kW}$ and $0.75 \Omega$ with aluminum heat sink are connected in parallel. Active cooling of the resistance group is provided by using a fan. In this way, the resulting temperature was kept below $50^{\circ} \mathrm{C}$.
SQD300AA100 Darlington power transistor module is used as a switching element [16]. With this module of $1000 \mathrm{~V}$ and $300 \mathrm{~A}$, switching is performed at a variable duty rate at a frequency of $1 \mathrm{kHz}$.

A diode module is connected in series to the circuit in order to prevent problems that may arise in case of incorrect connection of the battery bank. The circuit structure of the designed system is shown in Fig. 3.

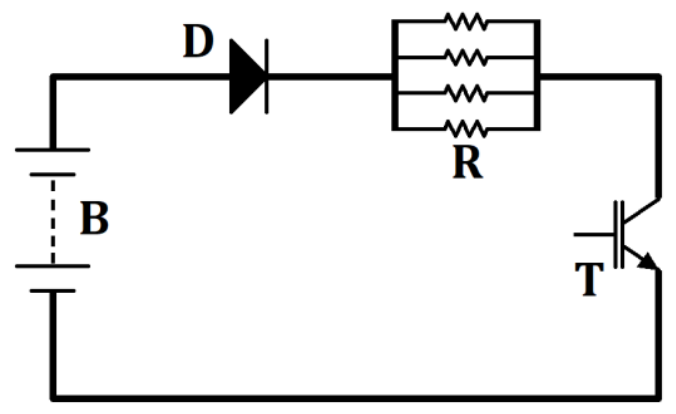

Figure. 3. The basic circuit structure of the designed system

The block diagram of the operation of the developed tester is given in Fig. 4. A special control card is designed in the Altium Designer program for manage the system. This board is managed by the PIC18F46K22 microcontroller manufactured by Microchip. It is an 8-bit microcontroller that operates at a frequency of $64 \mathrm{MHz}$. It has $10 \mathrm{bit}$ analog to digital converter and 10 bit PWM resolution [17-19]. On the board, there is a driving circuit for the transistor module, 2 serial ports, analog and digital inputs and outputs, 4 relay outputs and real time clock.

A sensor is used to measure the voltage and current. A digital temperature sensor was used to monitor the temperature of the resistance group.

With the test device developed, it was aimed to test all battery banks consisting of different battery types. While some batteries are not expected to heat up during discharge, some batteries can be heated up immediately depending on their health and chemical structure. A temperature sensor has been used to prevent negativity in case of warming the battery bank.

An HMI LCD was used to enter parameters before starting the test and to display parameters such as voltage, current, temperature and time during the test. This LCD is the NX8048K070-011C model manufactured by Nextion. It is 7.0" and capacitive touch. Interface is created in Nextion Editor Program [20-22]. In addition, during the test, all parameters are recorded on a micro SD card so that they can be recorded and evaluated later.

\section{PARAMETERS RELATED TO BATTERY TEST}

The load test is performed to test that the battery bank can supply enough power and energy when needed. The load is designed to represent the expected conditions under which battery banks can be used [23]. The parameters used to determine the health of a battery are described below.

State of Charge (SOC): Indicates the instantaneous capacity of the battery. In this way, the user can calculate how long the battery will supply the system with energy [24]. 


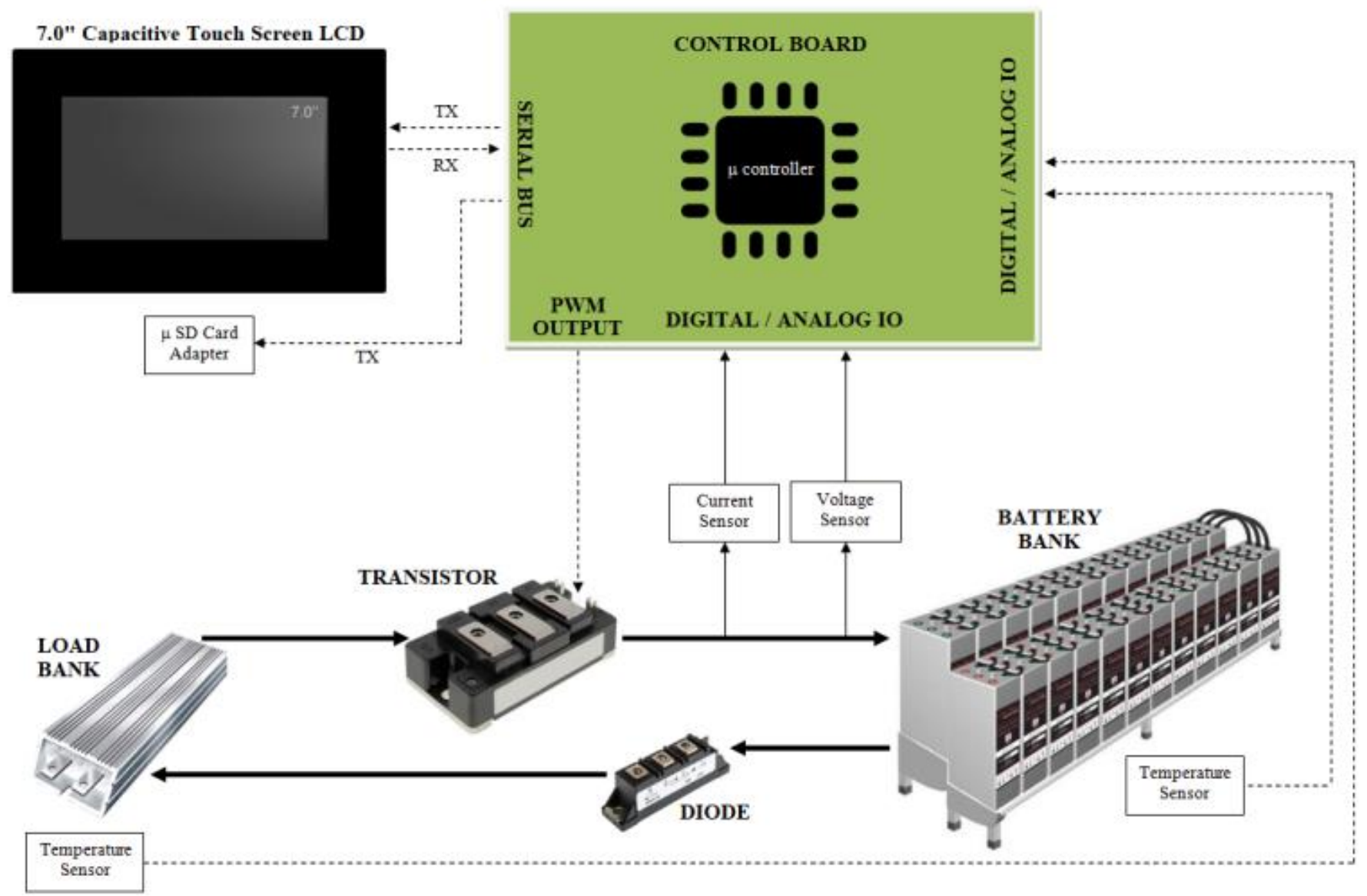

Figure. 4. The block diagram of the operation of the test device

State of health (SOH): Defines the comparison of battery performance with its new form. It is not an absolute measurement [25].

Capacity or Nominal Capacity (Ah): Defines the energy drawn from the battery when it is discharged from full charge voltage to cut off voltage. It is calculated by multiplying the discharge current by the discharge time [26].

Energy or Nominal Energy (Wh): Defines the energy drawn from the battery when it is discharged from full charge voltage to cut off voltage. It is calculated by multiplying the discharge power by the discharge time [26].

Cycle Life: Indicates the maximum number of charge discharges of the battery, provided that it meets certain performance criteria [26].

\section{EXPERIMENTAL RESULTS AND DISCUSSIONS}

Industrial banks, which have a cell voltage of $2 \mathrm{~V}$, were connected in series and battery banks were created. Many tests have been carried out with these battery banks. The data obtained from the tests are presented in Table 1.

As it is known, in load tests on batteries with lead acid chemistry, the amount of energy drawn and the voltage drop are directly proportional.

In tests 7 and 8 , two battery banks with $118 \mathrm{~V}$ charging voltage and $300 \mathrm{Ah}$ energy capacity were discharged at constant
$20 \mathrm{~A}$. The voltage of both battery banks was reduced to $104 \mathrm{~V}$. As a result of the test process, 190Ah energy was drawn from the battery bank used in test number 7, while 180Ah energy was drawn from the battery bank used in test number 8 . In this case, it is obvious that the battery bank used in the test number 8 is healthier.

Similarly, in tests 11 and 12, two battery banks with $112 \mathrm{~V}$ charge voltage and 200Ah energy capacity were discharged at a constant $10 \mathrm{~A}$. The voltage of both battery banks has been reduced to $102 \mathrm{~V}$. As a result of the test process, 95Ah energy was drawn from the battery bank used in test number 11, while $70 \mathrm{Ah}$ energy was drawn from the battery bank used in test number 12 . If a comparison is made, it can easily be said that the battery bank used in test number 12 is healthier. The voltage-time graph for tests 23 and 25 is presented in Fig. 5.

When a healthy battery is loaded with constant current, the voltage drop is expected to be very close to the line. In the graphic in the figure, a straight line is observed between $48 \mathrm{~V}$ $45 \mathrm{~V}$ as expected. However, a steeper and partially exponential curve is observed before $48 \mathrm{~V}$. This can be explained by the decrease in the life of both battery banks. 
TABLE I. Measurement data obtained with experimental test

\begin{tabular}{|c|c|c|c|c|c|c|}
\hline $\begin{array}{c}\text { Test } \\
\text { No }\end{array}$ & $\begin{array}{c}\text { Battery } \\
\text { Bank } \\
\text { Busbar } \\
\text { Voltage } \\
(\text { V) }\end{array}$ & $\begin{array}{c}\text { Battery } \\
\text { Bank } \\
\text { Capacity } \\
(\text { Ah })\end{array}$ & $\begin{array}{c}\text { Test } \\
\text { Current } \\
(\boldsymbol{A})\end{array}$ & $\begin{array}{c}\text { Test } \\
\text { Time } \\
(\boldsymbol{m i n})\end{array}$ & $\begin{array}{c}\text { Busbar } \\
\text { Voltage at the } \\
\text { End of the } \\
\text { Test }(\boldsymbol{V})\end{array}$ & $\begin{array}{c}\text { Drawn } \\
\text { Energy }\end{array}$ \\
\hline 1 & 120 & 200 & 10 & 720 & 104 & 120 \\
\hline 2 & 120 & 200 & 10 & 700 & 104 & 116.6 \\
\hline 3 & 120 & 200 & 10 & 615 & 106 & 102.5 \\
\hline 4 & 120 & 200 & 10 & 600 & 106 & 100 \\
\hline 5 & 120 & 200 & 10 & 600 & 108 & 100 \\
\hline 6 & 118 & 200 & 10 & 600 & 103 & 100 \\
\hline 7 & 118 & 300 & 20 & 570 & 104 & 190 \\
\hline 8 & 118 & 300 & 20 & 540 & 104 & 180 \\
\hline 9 & 118 & 200 & 10 & 600 & 104 & 100 \\
\hline 10 & 118 & 200 & 10 & 540 & 107 & 90 \\
\hline 11 & 112 & 200 & 10 & 570 & 102 & 95 \\
\hline 12 & 112 & 200 & 10 & 420 & 102 & 70 \\
\hline 13 & 112 & 200 & 8 & 630 & 105 & 84 \\
\hline 14 & 112 & 200 & 10 & 450 & 105 & 75 \\
\hline 15 & 112 & 200 & 8 & 570 & 106 & 76 \\
\hline 16 & 112 & 200 & 8 & 600 & 106 & 80 \\
\hline 17 & 110 & 200 & 10 & 500 & 102 & 83.3 \\
\hline 18 & 110 & 200 & 10 & 420 & 102 & 70 \\
\hline 19 & 110 & 200 & 10 & 360 & 102 & 60 \\
\hline 20 & 110 & 100 & 10 & 300 & 104 & 50 \\
\hline 21 & 50 & 200 & 10 & 620 & 42 & 103.3 \\
\hline 22 & 50 & 200 & 10 & 560 & 42 & 93.3 \\
\hline 23 & 50 & 200 & 10 & 600 & 45 & 100 \\
\hline 24 & 50 & 200 & 10 & 540 & 45 & 90 \\
\hline 5 & 50 & 200 & 10 & 420 & 45 & 70 \\
\hline
\end{tabular}

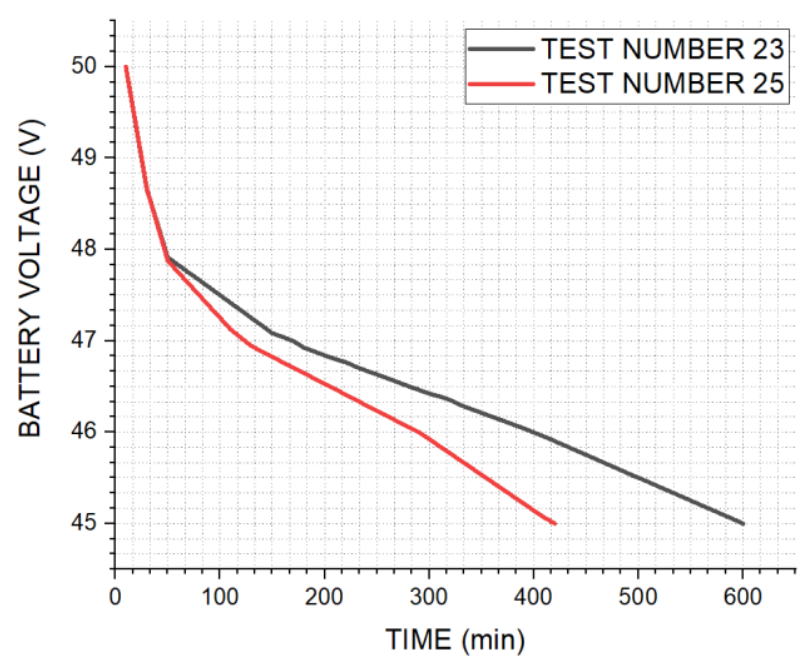

It can be seen that the battery bank used in the test number 25 reached a voltage of 45V 180 minutes ago. Battery banks have the same charge voltage, same capacity and are discharged at the same current. In this case, it can be said that the battery bank used in the test number 23 is healthier.

The oscilloscope view of the battery bank busbar voltage during the test is given in Fig. 6. At $115.75 \mathrm{~V}$ battery voltage, a $21 \mathrm{~V}$ fluctuation is observed from pick to pick during switching. This is an acceptable value and has no effect on the test result.

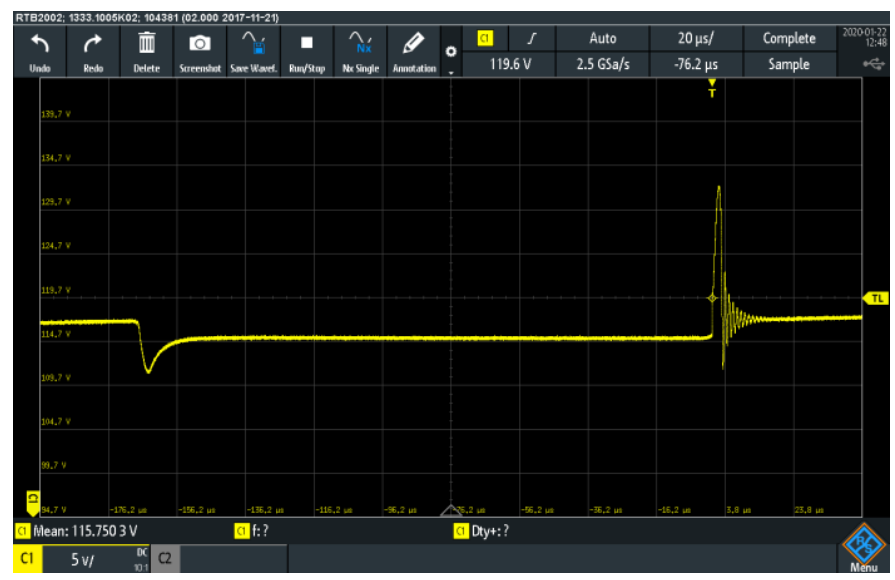

Figure. 6. Battery voltage on test

When the tests given in the Table 1 are grouped and examined as a whole, it is observed that batteries with the same chemical structures and technical specifications give different results when subjected to the same tests. This clearly shows that batteries with the same characteristics perform differently over time. Through the developed tester, these changes in battery performances can be detected. If these tests are not carried out, it is quite difficult to detect batteries that are damaged or have lost performance.

\section{CONCLUSION}

In this study, the battery banks were discharged with a constant current in the tests performed with the developed test device. Instant parameters are reported during the test. Based on these data, technical parameters of battery banks were obtained.

Numerous experimental tests have been carried out with the battery banks created by connecting industrial type aqueous batteries with a cell voltage of $2 \mathrm{~V}$ in series. The data obtained from the tests are presented in Table 1. Considering tests 21 and 22 , both battery banks were discharged to the cut-off voltage. The SOH value of the battery bank number 21 can be calculated as $51.5 \%$ and the SOH value of the battery bank number 22 can be calculated as $46.5 \%$. As expected, a straight curve is observed between $48 \mathrm{~V}-45 \mathrm{~V}$ on the voltage-time graph obtained for the tests 23 and 25 in this table. However, the formation of a steeper and partially exponential curve before $48 \mathrm{~V}$ can be explained by the decrease in the life of both battery banks.

Figure. 5. Voltage-time graph for tests 23 and 25 
When these tests are not carried out, it is quite difficult to detect batteries that are connected to a system, that are damaged or have lost performance. It can result in data loss and financial losses in a UPS system, financial losses and serious injuries in systems connected to power transmission lines.

Many studies have been conducted that can test a single cell, specific to different battery structures. However, in large scale battery banks, it takes a lot of time to test each cell individually. The developed tester provides a great advantage thanks to its ability to test at high current and high voltage as well as to be adjusted for different battery structures and automatic operation.

The next step of the future study is to measure and report each cell voltage individually. In this way, broken cells can be easily detected.

\section{ACKNOWLEDGMENT}

This study was supported by Karamanoglu Mehmetbey University Scientific Research Projects Coordination Unit (Project Number: 28-YL-19).

\section{REFERENCES}

[1] I. Sefa, S. Balci, N. Altin, and S. Ozdemir, Comprehensive analysis of inductors for an interleaved buck converter. 2012, pp. DS2b.5-1.

[2] T. Blank, J. Badeda, J. Kowal, and D. Sauer, Deep discharge behavior of lead-acid batteries and modeling of stationary battery energy storage systems. 2012.

[3] E. Oguz, H. Çimen, and Y. Oğuz, "Simulation and Power Flow Control Using Switching's Method of Isolated WindSolar Hybrid Power Generation System with Battery Storage," Balkan Journal of Electrical and Computer Engineering, pp. 40-49, 09/01 2017, doi: 10.17694/bajece. 334348 .

[4] N. Altin, S. Balci, S. Ozdemir, and I. Sefa, "A comparison of single and three phase DC/DC converter structures for battery charging," in 2013 International Conference on Renewable Energy Research and Applications (ICRERA), 20-23 Oct. 2013 2013, pp. 1228-1233, doi: 10.1109/ICRERA.2013.6749939.

[5] M. Kiel, D.-U. Sauer, P. Turpin, M. Naveed, and E. Favre, "Validation of single frequency $\mathrm{Z}$ measurement for standby battery state of health determination," INTELEC 2008 2008 IEEE 30th International Telecommunications Energy Conference, pp. 1-7, 2008.

[6] H. K. Scholl, "Automatic battery tester with recording means for battery performance," ed: Google Patents, 1971.

[7] N. C. Berglund, T. J. Rosedahl, and S. W. Steele, "Battery capacity test and electronic system utilizing same," ed: Google Patents, 1997.

[8] K. I. Bertness, "Method and apparatus for auditing a battery test," ed: Google Patents, 2000.

[9] G. D. Brink and D. L. Burton, "Battery capacity test method and apparatus," ed: Google Patents, 2000.

[10] A. H. Anbuky and P. E. Pascoe, "Battery capacity measurement," ed: Google Patents, 2005.

[11] M. Coleman, W. G. Hurley, and C. K. Lee, "An Improved Battery Characterization Method Using a Two-Pulse Load Test," IEEE Transactions on Energy Conversion, vol. 23, no. 2, pp. 708-713, 2008, doi: 10.1109/TEC.2007.914329.
[12] M. B. Bayram, I. Sefa, and S. Balci, "A static exciter with interleaved buck converter for synchronous generators," International Journal of Hydrogen Energy, vol. 42, no. 28, pp. 17760-17770, 2017/07/13/ 2017, doi: https://doi.org/10.1016/j.ijhydene.2017.03.062.

[13] S. Ozdemir, S. Balci, N. Altin, and I. Sefa, "Design and performance analysis of the three-level isolated DC-DC converter with the nanocyrstalline core transformer," International Journal of Hydrogen Energy, vol. 42, no. 28, pp. 17801-17812, 2017/07/13/ 2017, doi: https://doi.org/10.1016/j.ijhydene.2017.02.158.

[14] F. Asadi and K. Eguchi, "On the extraction of input and output impedance of PWM DC-DC converters," Balkan Journal of Electrical and Computer Engineering, vol. 7, 04/30 2019, doi: 10.17694/bajece.468787.

[15] R. Bououd and S. Lassaad, An overview of chopper topologies. 2017, pp. 1-7.

[16] SANREX. "SQD300AA100 Transistor Module." https://www.digchip.com/datasheets/download_datasheet.p hp?id=919058\&part-number=SQD300AA100 (accessed 2019).

[17] Altium. "Altium Designer." https://www.altium.com/altium-designer/ (accessed 2020).

[18] Microchip. "Microchip." https://www.microchip.com/ (accessed 2020).

[19] Microchip. "PIC18F46K22 Microcontroller." https://www.microchip.com/wwwproducts/en/PIC18F46K 22\#additional-features (accessed 2020).

[20] Nextion. "Home - Nextion." https://nextion.tech/ (accessed 2020).

[21] Nextion. "NX8048k070 - Nextion." https://nextion.tech/datasheets/nx8048k070/ (accessed 2020).

[22] Nextion. "Nextion Editor." https://nextion.tech/nextioneditor/\#section 1 (accessed 2020).

[23] Electropaedia. "Battery Testing." https://www.mpoweruk.com/testing.htm (accessed 2019).

[24] Electropaedia. "State of Charge (SOC) Determination." https://www.mpoweruk.com/soc.htm (accessed 2019).

[25] Electropaedia. "State of Health ( $\mathrm{SOH})$ Determination." https://www.mpoweruk.com/soh.htm (accessed 2019).

[26] M. Team, "A guide to understanding battery specifications," 2008.

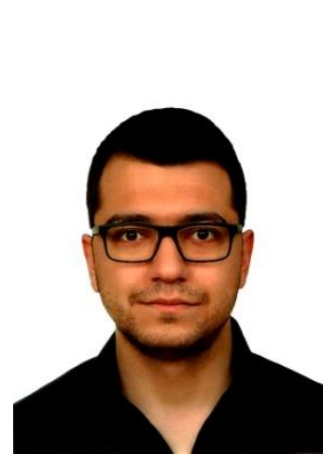

\section{BIOGRAPHIES}

ZEKI ZUREY He was born in 1991. He received the B.S. degree in Electrical and Electronics Engineering (EEE) from Gazi University, Ankara, in 2014. He is a graduate student in the department of Karamanoğlu Mehmetbey University EEE. His research interests include power electronics circuits, electric vehicles, hardware design, programming, industrial electronics and agricultural electronics. 


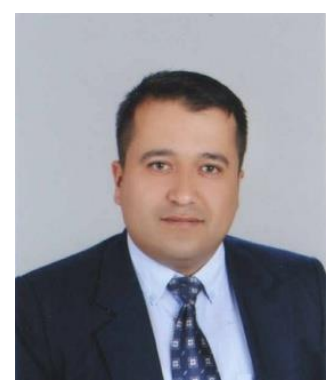

KADIR SABANCI He was born in 1978. He received his B.S. and M.S. degrees in Electrical and Electronics Engineering (EEE) from Selcuk University, Turkey, in 2001, 2005 respectively. In 2013, he received his Ph.D. degree in Agricultural Machineries from Selcuk University, Turkey. He has been working as Assistant Professor in the Department of EEE at Karamanoglu Mehmetbey University. His current research interests include image processing, data mining, artificial intelligent, embedded systems and precision agricultural technology.

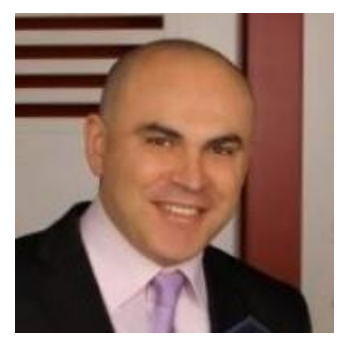

SELAMI BALCI He received the B.S., M.S. and the Ph.D. degrees in electrical education from the Gazi University, Ankara, in 1997, 2010 and 2016, respectively. Since 2018, he is currently an assistant professor at the faculty of engineering, department of electrical and electronics engineering,

Karamanoglu Mehmetbey University. His research interests include medium frequency power transformer, transformer design with the soft magnetic core material, transformer thermal analysis, inductor design, electromagnetic modeling with FEA software, and performance analysis of the power electronics circuits. 